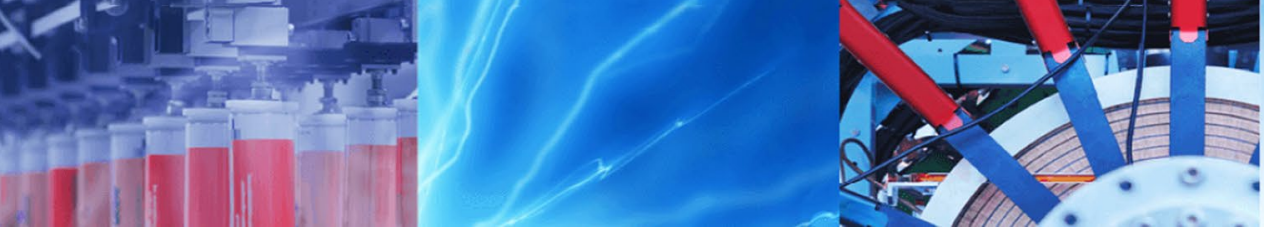

Research Article

\title{
Numerical evaluation of lightweight ultra high strength steel sandwich for energy absorption
}

\author{
Samuel Hammarberg ${ }^{1}\left[\right.$ D Simon Larsson ${ }^{1} \cdot$ Jörgen Kajberg $^{1} \cdot$ Pär Jonsén ${ }^{1}$
}

Received: 29 May 2020 / Accepted: 15 October 2020 / Published online: 24 October 2020

(c) The Author(s) 2020 OPEN

\begin{abstract}
Legislation regarding greenhouse gas emissions forces automotive manufacturers to bring forth new and innovative materials and structures for weight reduction of the body-in-white. The present work evaluates a lightweight ultra high strength steel sandwich concept, with perforated cores, for energy absorption applications. Hat-profile geometries, subjected to crushing, are studied numerically to evaluate specific energy absorption for the sandwich concept and solid hat-profiles of equivalent weight. Precise discretization of the perforated core requires large computational power. In the present work, this is addressed by homogenization, replacing the perforated core with a homogeneous material with equivalent mechanical properties. Input data for the equivalent material is obtained by analyzing a representative volume element, subjected to in-plane loading and out-of-plane bending/twisting using periodic boundary conditions. The homogenized sandwich reduces the number of finite elements and thereby computational time with approximately $95 \%$, while maintaining accuracy with respect to force-displacement response and energy absorption. It is found that specific energy absorption is increased with $8-17 \%$, when comparing solid and sandwich hat profiles of equivalent weight, and that a weight saving of at least $6 \%$ is possible for equivalent performance.
\end{abstract}

Keywords UHSS · Sandwich · Lightweight $\cdot$ Modeling $\cdot$ RVE

\section{Introduction}

The automotive industry faces long-term goals regarding reduction of greenhouse gas (GHG) emissions. Effort is therefore put into finding new design solutions and material selections, reducing the life-cycle ecological footprint through energy efficient production and reduced weight of e.g. body-in-white parts (BIW). At the same time, innovative design and new materials have to fulfill the demand regarding final product performance, such as crashworthiness.

Steel, a common material in many sectors, due to its high strength to cost ratio, has been utilized for manufacturing lightweight components by various methods of heat treatment. According to Kawajiri et al. [1], replacing mild steel with high strength steel has been one of the most effective material substitutions with regard to lowering GHG emissions. In the 1970's, press hardening was invented by Luleå university of technology and NJA (now SSAB) and industrialized by Plannja HardTech (now Gestamp Hardtech). In the press hardening process, a blank is austenitized and quenched, forming a mainly martensitic microstructure. The result is an ultra high strength steel (UHSS) with high shape accuracy, suitable for intrusion protection in vehicles. Due to the superior mechanical properties of UHSS, gauge thicknesses can be reduced, thus lowering the weight of the BIW. Karbasian and Tekkaya [2] describe the process steps of the methods, providing an insight into the method of press hardening. By controlling the temperature gradients of the tools, tailored microstructures are attainable for the hot formed components. Such components are desirable since the

Samuel Hammarberg, samuel.hammarberg@ltu.se | 'Luleå University of Technology, Universitetsvägen, Luleå, Sweden. 
varying mechanical properties can be utilized for passenger safety by optimizing structural integrity and energy absorption. Extensive research has been carried out on UHSS for predicting the microstructure evolution during forming, fracture and fatigue. Models for predicting microstructure evolution has been carried out by several authors, e.g. Oldenburg and Lindkvist [3], and an overview of modeling of press hardening has been given by Oldenburg [4] and Merklein et al. Merklein et al. [5]. Research on modeling fracture in UHSS has been studied by several authors. Östlund et al. [6] suggest a strain based failure criteria, dependent on stress triaxiality and independent of element size, for shell elements. Good agreement was found between numerical and experimental tensile test results. The fracture toughness of low alloyed boron steel with varying microstructures was studied by Golling et al. [7], providing a better understanding of fracture initiation and allowing for manufacturing of components with improved crashworthiness. In Golling et al. [8] fracture toughness was studied under varying strain rates for different grades of high strength steels. It was found that the crack propagation resistance increased with the strain rate.

An additional method for reducing vehicle weight is incorporation of sandwich structures into the BIW, see e.g. the work by Hara and Özgen [9] and Balakrishnan et al. [10]. A typical sandwich consists of stiff face plates separated by a lightweight core. The ideal core has the lowest possible weight with sufficient stiffness to withstand transverse and shear loads, maintaining the initial distance between the face plates. A wide range of cores exist, such as foams, geometrical patterns, and solid cores.

Foam has been studied by several authors, and it was shown by Gibson [11] that the mechanical properties of foams are strongly influenced by the bulk material. Thus, the selection of bulk material is of importance when the foam is selected. A review of steel foam was done by Smith et al. [12], including manufacturing processes and structural applications. Additional work regarding steel foam was conducted by Park and Nutt [13], Smith et al. [14], Szyniszewski et al. [15] and Szyniszewski et al. [16]. Zhang et al. [17] studied aluminum foam experimentally, identifying parameters for constitutive modeling. Sulong et al. [18] studied advanced pore morphology foam elements in compression, using experiments and numerical methods. Xiao et al. [19] studied aluminum foam filled bumper beams for energy absorption. Micromechanical models were adopted by Marsavina et al. [20] for predicting mechanical properties of foam. Özer et al. [21] studied syntactic foams in crash boxes for energy absorption.

Honeycomb cores subjected to crushing were studied by Aktay et al. [22], where methods of modeling honeycomb were validated by experiments, with good agreement. Nayak et al. [23] utilized honeycomb sandwich panels and illustrated their use for blast load mitigation. Additional work on honeycomb was conducted by Sun et al. [24]. The study contributed to increase the knowledge of crashworthiness and collapse modes of honeycomb cores. Honeycomb patterns were also studied by Wu et al. [25], where various honeycomb geometries were investigated at low impact velocities. The core consisted of aluminum whereas carbon reinforced polymer (CFRP) was used as face plates, which was compared to a panel solely based on CFRP. The increased performance of the sandwich, with respect to crashworthiness, was evident. Hammarberg et al. [26] manufactured a UHSS sandwich panel with a bidirectionally corrugated core, intended for stiffness applications. Homogenization of the core was carried out by analyzing a representative volume element under periodic boundary conditions, reducing computational time with maintained accuracy.

In the work by Mohr and Wierzbicki [27], a sandwich based on a perforated, shear-rigid, core was studied numerically for crash box columns. The perforated core was modeled as a continuum, using a honeycomb material model. Detailed modelling, with precise discretization of the perforated core, was not included to check the accuracy of the honeycomb model. The box columns were loaded axially and specific energy absorption was studied for a set of sandwich cores. No increases in specific energy was observed for the numerical models. Furthermore, it was discussed by the authors that skin fracture is likely to occur and must therefore be taken into account when predicting sandwich performance.

The present work suggests a lightweight UHSS sandwich concept with a perforated core, similar to what was studied by Mohr and Wierzbicki [27], for energy absorption applications. Thus, combining the benefits of UHSS and sandwich structures. The concept is investigated numerically by subjecting sandwich hat-profiles to a quasi-static crushing load using the finite element method (FEM). The obtained energy absorption is compared to solid hat-profiles of equivalent weight. Accuracy of the predicted sandwich performance is improved by including an incremental stress state dependent damage model. Failure strain is prescribed dependent on stress triaxiality, allowing for study of skin fracture. Precise discretization of the core, using solid finite elements, causes long computational time. To address this, the core is homogenized using an equivalent material formulation, greatly reducing the number of finite elements and thereby computational time. Input data for the equivalent material is obtained by characterizing a representative volume element (RVE) for in-plane loading and out-of-plane bending/twisting, using periodic boundary conditions. From the RVE analysis equivalent properties for the perforated sections of the core are determined The objectives of the paper 
is to investigate if the sandwich concept can be utilized for increasing specific energy absorption of hat-profiles, and to study if homogenization can be utilized for reducing computational time while maintaining accuracy. The novelty of the work lies in the study of a UHSS sandwich concept, intended for energy absorption, using refined finite element models with the inclusion of skin fracture, as well as homogenization of the perforated core using a stress-resultant based equivalent representation.

Following the introduction is a section describing the finite element models of the study, where the detailed models are presented as well as the damage model and the homogenization procedure. This is followed by a discussion of the results as well as conclusions drawn.

\section{Finite element modeling}

In the present section, the finite element models used for studying the energy absorption of the sandwich hatprofile are introduced in Fig. 1. The geometry and material of the sandwich hat-profiles are presented in Sect. 2.1. A parameter study is also conducted and presented in the section, investigating how the sandwich constituents contribute to the energy absorption. This is followed by a presentation of the detailed finite element models used for analyzing energy absorption, see Sect. 2.2. In the detailed models, core and skins are represented by solid- and shell elements respectively. The performance of sandwiches is limited by their failure modes, such as skin fracture, shear failure of the core and delamination. In the detailed FE models, skin fracture is studied by including an incremental stress-state dependent damage model, calibrated for plane stress, described in Sect. 2.3. Inclusion of a damage model for the skins is necessary since sandwich structures are generally thicker than the component it is replacing, and thus more likely to fail under fracture. By including the damage model it is possible to approximately predict the amount of energy the sandwich can absorb before skin failure, at which point the simulations are terminated. Core

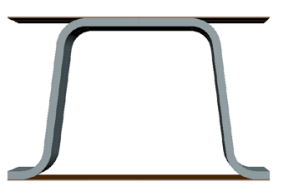

(a)

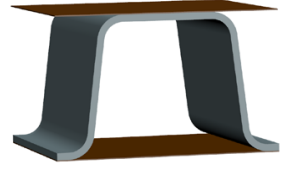

(b)
Fig. 1 The UHSS sandwich concept is evaluated by subjecting a hat-profile geometry to crushing. A frontal view is presented in a and a perspective view is presented in $\mathbf{b}$. The barrier on top crushes down on the hat profile, while the flange edges are clamped and the support below is fully fixed failure and delamination are excluded from the FE analysis. The absorbed energy is compared to the performance of a solid hat-profile of equivalent weight and intrusion. The results indicate if the presented sandwich concept is a realistic contender for lightweight energy absorption applications. A large amount of solid finite elements are required for precise discretization of the perforated core in the detailed models, causing long computational times. To address this issue, the perforated sections of the core are homogenized, using a stress-resultant based constitutive model, with equivalent mechanical properties to that of the perforated section of the core. Equivalent material data is obtained by subjecting a representative volume element to periodic boundary conditions from which desired data is extracted, presented in the final part of this section. All simulations are run using the multi-physics solver LS-DYNA R11.0 [28]. Explicit- and implicit time integration are used for the hat-profiles and RVE analysis, respectively.

\subsection{Geometries and materials}

The middle surface of the hat-profile geometry is presented in Fig. 2. Due to symmetry a quarter model is utilized. Dimensions and planes of symmetry are presented in Fig. 2a, b. Thicknesses of core and skins are varied in the study, see Table 1 and Fig. 2c. The core of the sandwich consists of perforated sections, see Fig. $2 d$, which are only placed over the plane sections and not the radii, forming a partly perforated core. For the perforated sections of the core, the relative core density, $\rho^{*}$, is defined as the ratio between the densities of the core, $\rho_{\text {core }}$ and the bulk material, $\rho_{\text {bulk}}$, according to

$\rho^{*}=\frac{\rho_{\text {core }}}{\rho_{\text {bulk }}}$.

Equation (1) is rewritten in terms of the hole diameter, $D$, the spacings $d_{A}$ and $d_{C}$, and the angle, $\alpha$ (see Fig. $2 \mathrm{~d}$ )

$\rho^{*}=1-\frac{D^{2} \pi}{8\left(\frac{d_{A}+D}{2}\right)\left[\left(d_{C}+D\right)^{2}-\left(\frac{d_{A}+D}{2}\right)^{2}\right]^{1 / 2}}$.

where

$d_{C}=\frac{d_{A}+D}{2 \cos (\alpha)}-D$

In accordance with Mohr and Wierzbicki [27], the limiting case is when the spacing between the holes approaches zero $\left(d_{A}=d_{C}=0\right.$ and $\left.\alpha=60^{\circ}\right)$, corresponding to a relative core density, $\rho^{*}$, of $9.3 \%$ for the perforated sections of the core. 


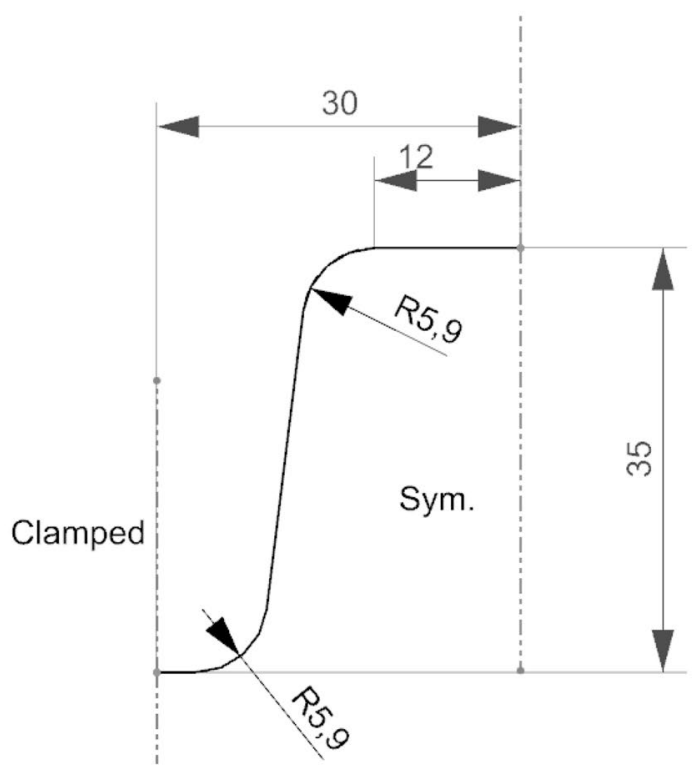

(a)

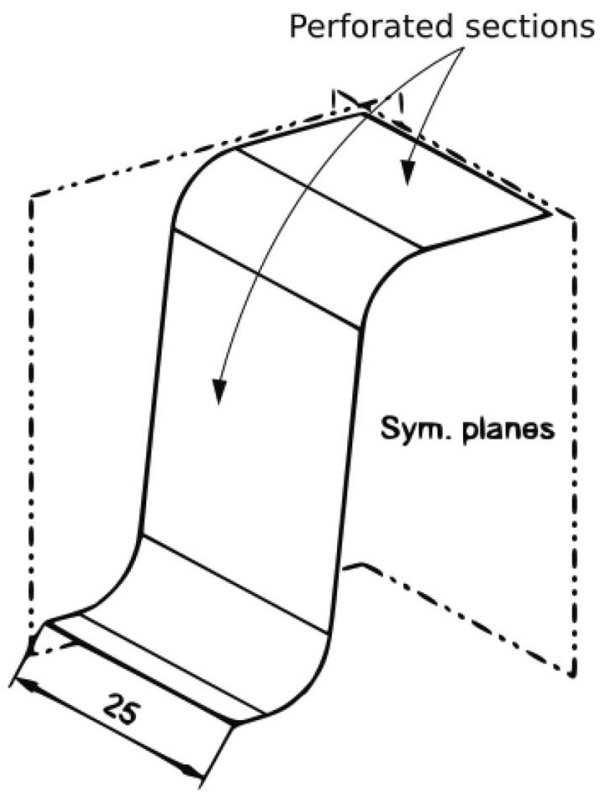

(b)

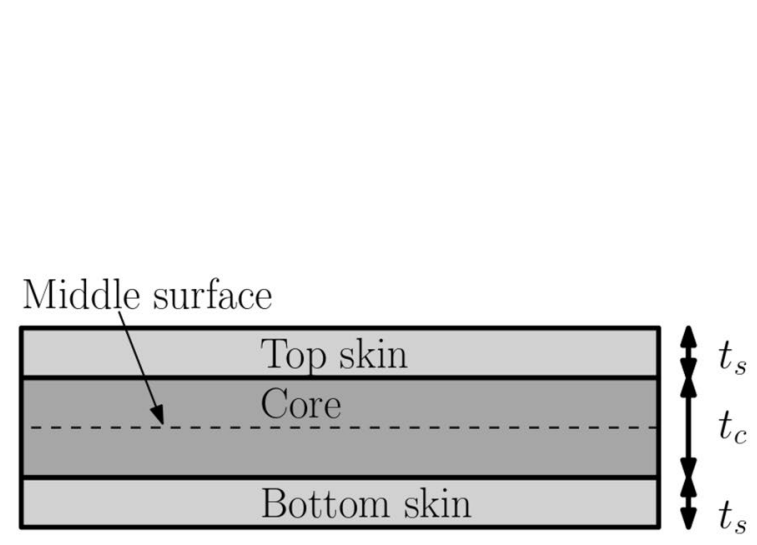

(c)

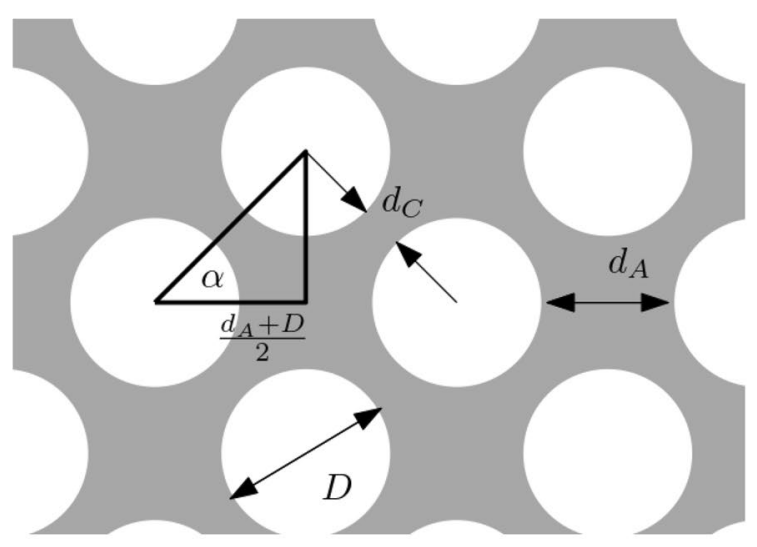

(d)

Fig. 2 The middle surface of the hat profile is presented in $\mathbf{a}$ and $\mathbf{b}$ with the symmetry planes marked. The three layers of the sandwich are presented in $\mathbf{c}$ with their corresponding thicknesses. In $\mathbf{d}$ the structure of the perforated sections of the core is presented

Two different hole diameters are used for the sandwich: $3 \mathrm{~mm}$ and $1.5 \mathrm{~mm}$. The size of the hole diameters are chosen to be relatively small compared to the overall structure of the hat-profile, while still not requiring tremendous amounts of finite elements for geometrical resolution. Three parameters are varied to investigate their influence on the energy absorption and fracture of the sandwich with a hole diameter of $3 \mathrm{~mm}$. The parameters studied are the hole distribution, $d_{A^{\prime}}$ core/skin distribution with maintained initial thickness, and reduced total thickness of the sandwich while maintaining initial distribution between core and skins. The last parameter is also investigated for a hole diameter of $1.5 \mathrm{~mm}$. The angle, $\alpha$, is kept constant at $45^{\circ}$ and $d_{C}$ is determined from Eq. (3). A summary of the tested parameters is presented in Table 1, where it should be noted that the mass presented corresponds to a quarter of the mass of the hat profile according to the symmetry conditions used in the numerical models. The entire sandwich is based on the fully hardened UHSS, $22 \mathrm{MnB5}$. Young's modulus and density is $200 \mathrm{GPa}$ and $7800 \mathrm{~kg} / \mathrm{m}^{3}$ respectively and Poison's ratio is 0.3 .

\subsection{Detailed finite element models}

Hat-profiles, subjected to crushing, are used to numerically study the energy absorption of the UHSS sandwich. A quarter finite element model of a hat profile is presented in Fig. 3. Planes of symmetry are indicated in Fig. 2a and 
Table 1 Geometric data for the perforated sections of the sandwich core

\begin{tabular}{lllllllll}
\hline Sandwich & $t_{\text {tot }}(\mathrm{mm})$ & $t_{s}(\mathrm{~mm})$ & $t_{c}(\mathrm{~mm})$ & $D(\mathrm{~mm})$ & $d_{A}(\mathrm{~mm})$ & $\alpha$ & $\mathrm{m}(\mathrm{g})$ & $\rho^{*}(-)(\%)$ \\
\hline$\# 1$ & 1.848 & 0.308 & 1.232 & 3 & 3 & 45 & 17.9 & 60.7 \\
$\# 2$ & 1.386 & 0.231 & 0.924 & 3 & 3 & 45 & 13.4 & 60.7 \\
$\# 3$ & 0.924 & 0.154 & 0.656 & 3 & 3 & 45 & 8.95 & 60.7 \\
$\# 4$ & 1.848 & 0.308 & 1.232 & 3 & 2.25 & 45 & 17.6 & 48.7 \\
$\# 5$ & 1.848 & 0.308 & 1.232 & 3 & 3.75 & 45 & 18.9 & 69.0 \\
$\# 6$ & 1.848 & 0.462 & 0.924 & 3 & 3 & 45 & 18.6 & 60.7 \\
$\# 7$ & 1.848 & 0.154 & 1.540 & 3 & 3 & 45 & 17.2 & 60.7 \\
$\# 8$ & 1.848 & 0.308 & 1.232 & 1.5 & 1.5 & 45 & 17.9 & 60.7 \\
$\# 9$ & 1.386 & 0.231 & 0.924 & 1.5 & 1.5 & 45 & 13.4 & 60.7 \\
$\# 10$ & 0.924 & 0.154 & 0.656 & 1.5 & 1.5 & 45 & 8.95 & 60.7 \\
$\# 11$ & 1.355 & 0.308 & 0.739 & 3.0 & 3.0 & 45 & 16.9 & 60.7 \\
\hline
\end{tabular}

In the table, $t_{\text {tot }}, t_{s}, t_{c}$ and $m$ correspond to total sandwich thickness, skin thickness, core thickness and sandwich mass respectively. $D, d_{A}$ and $\alpha$ are according to Fig. $2 d$, and $\rho^{*}$ according to Eq. (2) constrained accordingly. The flange nodes on the bottom left edge, indicated in Fig. 2a, are fully constrained. Contact is handled by a penalty based algorithm. Representation of the UHSS is achieved by a piece-wise linear plasticity material model where yield stress is prescribed as a function of effective plastic strain, see Fig. 4. Additional material parameters given are Young's modulus, Poisson's ratio and mass density. The velocity of the barrier is ramped up and the support is fixed. Both barrier and support are modeled as rigid bodies.

To ensure quasi-static conditions, i.e. inertia forces and kinetic energy may be neglected, sandwich \#1 of Table 1 is analyzed by subjecting it to the three velocity curves of Fig. 7a. By comparing the quotient between kineticand internal energy, as well as the force-displacement response, quasi-static conditions can be ensured.

The sandwich core of the hat-profile is discretized using fully integrated 8-node solid elements, whereas plane stress shell elements are used for the skins. During crushing the hat-profile is subjected to bending. To resolve the bending mode and ensure mesh independent results a convergence check is conducted regarding the required number of solid elements through the thickness. This is done by studying a sandwich consisting of solid finite elements. Brick elements with equal side lengths are utilized, starting with one element through the thickness. For each subsequent mesh refinement, the number of elements through the thickness is doubled. Evaluation of mesh convergence is done by comparing internal energies and force-displacement response, computational time is also considered.

\subsection{Modeling of fracture}

To account for skin fracture, a generalized incremental stress-state dependent damage model (GISSMO) is utilized
[28]. The fracture model allows for an incremental formulation of the damage accumulation, $\Delta D$, according to

$\Delta D=\frac{\kappa \cdot D^{\left(1-\frac{1}{\kappa}\right)}}{\epsilon_{f}} \Delta \epsilon_{p}$

In Eq. (4), $D$ corresponds to the damage value in the interval $0 \leq D \leq 1$, where elements are deleted if $D=1 . \kappa$ is a damage parameter, $\Delta \epsilon_{p}$ is the incremental plastic strain, $\epsilon_{f}$ is the equivalent plastic failure strain of Fig. 5. The data of the figure is obtained by calibration against tensile specimens according to [29] using LS-OPT. The equivalent plastic failure strain can be given as a function of both stress triaxiality, $\eta$, and the Lode parameter, $L$, determined as

$\eta=\frac{\sigma_{k k}}{\sqrt{\frac{3}{2} J_{2}}}$

$L=\cos (3 \theta)=\frac{3 \sqrt{3}}{2} \frac{J_{3}}{J_{2}^{3 / 2}}$

where $\sigma_{i j}$ corresponds to the Cauchy stress tensor, $J_{2}$ to the second deviatoric stress invariant, $\theta$ to the Lode angle (counterclockwise angle from the first principal stress axis in the deviatoric plane) and $J_{3}$ to the third deviatoric stress invariant. To account for instability and localization, the instability measure, $F$, is defined in an incremental formulation according to

$\Delta F=\frac{\kappa \cdot F^{\left(1-\frac{1}{\kappa}\right)}}{\epsilon_{p, l o c}} \Delta \epsilon_{p}$.

where $F$ is in the range of $0 \leq F \leq 1 . \epsilon_{p, l o c}$ is the equivalent plastic instability strain of Fig. 5 , and similarly to $\epsilon_{f}$ it can be given as a function of triaxiality and the Lode parameter. 


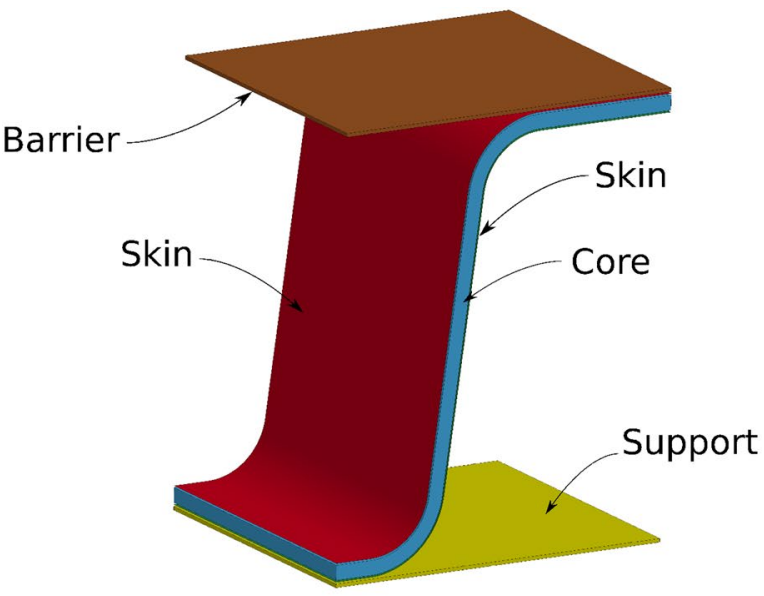

(a)

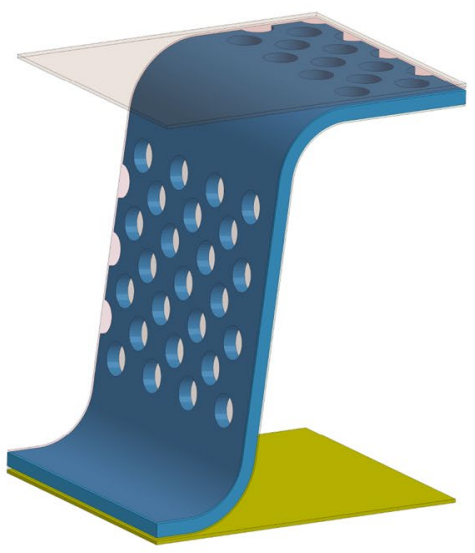

(b)

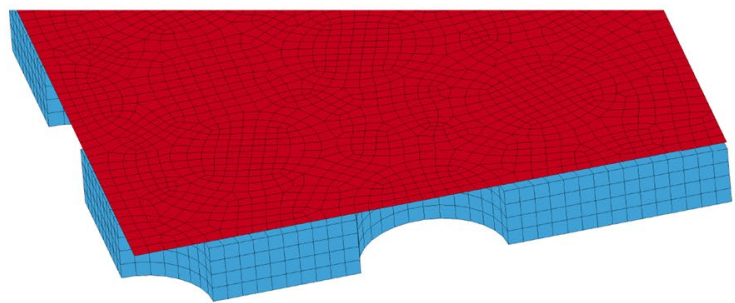

(c)

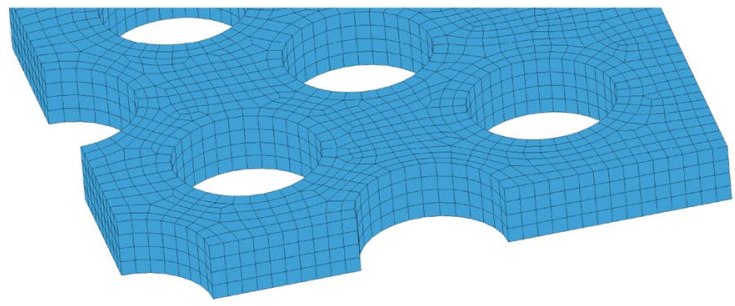

(d)

Fig. 3 Quarter finite element model of the hat profile is presented in $\mathbf{a}$. The perforations of the core are illustrated in $\mathbf{b}$. In $\mathbf{c}$, $\mathbf{d}$ the mesh of the hat profile is shown in greater detail

Once $F$ has reached unity, the current value of $D$ is stored, and from this point coupled to the flow stress.

Calibration of the fracture model can be performed by using the force-displacement response from the five specimens presented in [29]. The curves for plastic failure strain, $\epsilon_{f}$, and the plastic instability strain, $\epsilon_{p, l o c}$, were determined by inverse modeling using LS-OPT [30].

\subsection{Homogenized finite element model}

Using solid elements for detailed discretization of the sandwich core results in long computational times. To address this issue, the perforated regions of the core (see Fig. 3b) are homogenized using a stress-resultant based constitutive model, implemented for shell elements. Modeling of the solid regions of the core is done by the piece-wise linear plasticity model presented in Sect. 2.2. The stress-resultant model treats in-plane behavior separately from bending, typically necessary for perforated materials where differences in the elastic constants, such as Young's modulus, may differ greatly for in-plane loading and bending. The in-plane, plane stress elastic tensor, $\boldsymbol{C}^{p}$, is defined as 


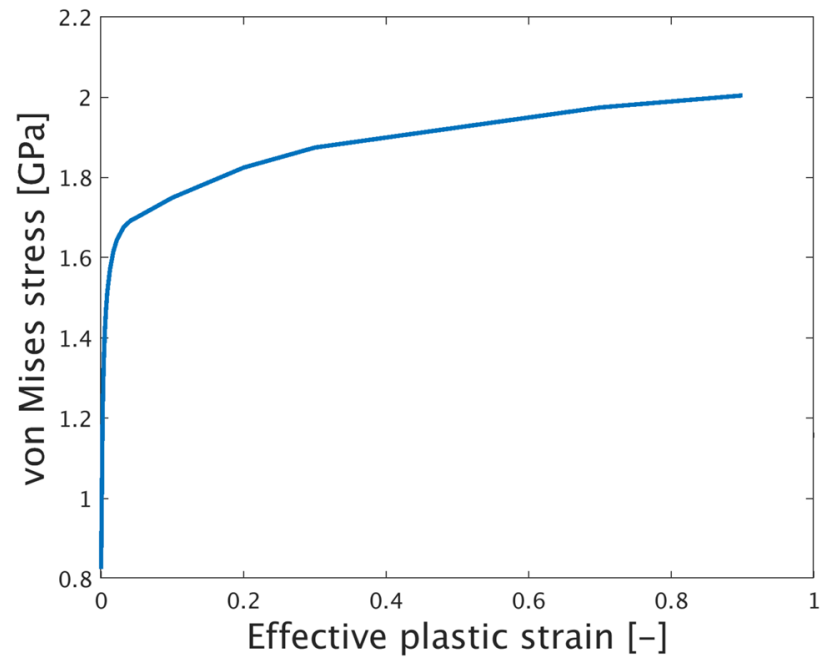

Fig. 4 Yield stress versus effective plastic strain for the ultra high strength steel

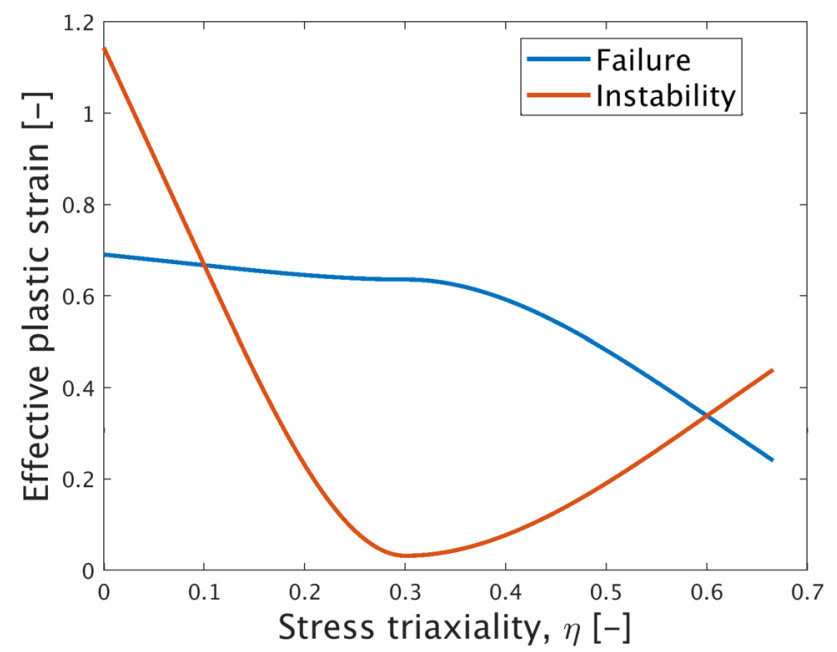

Fig. 5 Failure and instability curves used for the GISSMO damage model

$$
\boldsymbol{C}^{p}=\left[\begin{array}{ccccc}
Q_{11}^{p} & Q_{12}^{p} & 0 & 0 & 0 \\
Q_{12}^{p} & Q_{22}^{p} & 0 & 0 & 0 \\
0 & 0 & Q_{44}^{p} & 0 & 0 \\
0 & 0 & 0 & Q_{55}^{p} & 0 \\
0 & 0 & 0 & 0 & Q_{66}^{p}
\end{array}\right]
$$

where out of plane shear is accounted for by $Q_{55}$ and $Q_{66}$. The constituents of the matrix are given by

$$
\begin{gathered}
Q_{11}^{p}=\frac{E_{11}^{p}}{1-v_{12}^{p} p_{21}^{p}}, Q_{22}^{p}=\frac{E_{22}^{p}}{1-v_{12}^{p} p_{21}^{p}}, Q_{12}^{p}=\frac{v_{12}^{p} E_{11}^{p}}{1-v_{12}^{p} p_{21}^{p}} \\
Q_{44}^{p}=G_{12}^{p}, \quad Q_{55}^{p}=G_{23}^{p}, \quad Q_{66}^{p}=G_{31}^{p}
\end{gathered}
$$

$E_{11}^{p} E_{22}^{p}$ and $v_{12}^{p}$ correspond to the in-plane Young's moduli and Poisson's ratio, respectively. $G_{12}^{p}$ is the in-plane shear modulus whereas $G_{23}^{p}$ and $G_{32}^{p}$ correspond to the transverse shear moduli. The elastic tensor for bending is defined as

$\boldsymbol{c}^{b}=\left[\begin{array}{ccc}Q_{11}^{b} & Q_{12}^{b} & 0 \\ Q_{12}^{b} & Q_{22}^{b} & 0 \\ 0 & 0 & Q_{44}^{b}\end{array}\right]$

with its constituents given by

$Q_{11}^{b}=\frac{E_{11}^{b}}{1-v_{12}^{b} v_{21}^{b}}, Q_{22}^{b}=\frac{E_{22}^{b}}{1-v_{12}^{b} v_{21}^{b}}$
$Q_{12}^{b}=\frac{\nu_{12}^{b} E_{11}^{b}}{1-v_{12}^{b} b_{21}^{b}} \quad Q_{44}^{b}=G_{12}^{b}$

$E_{11^{\prime}}^{b} E_{22^{\prime}}^{b} G_{12}^{b}$ and $v_{12}^{b}$ are the Young's moduli, shear modulus and Poisson's ratio for bending. To account for plasticity, uncoupled yield curves are defined for the resultants. The resultants are coupled to the elastic tensors of Eqs. (8) and (10), as defined in laminate theory [31], in the following manner

$\left[\begin{array}{l}N \\ M\end{array}\right]=\left[\begin{array}{ll}A & B \\ B & D\end{array}\right]\left[\begin{array}{l}\epsilon \\ K\end{array}\right]$

where $\boldsymbol{N}$ and $\boldsymbol{M}$ are the membrane forces and bending moments, whereas $\boldsymbol{\epsilon}$ and $\boldsymbol{\kappa}$ are the in-plane strains and curvatures. In the present context $\boldsymbol{B}=\mathbf{0}$ and $\boldsymbol{A}$ and $\boldsymbol{D}$ are defined as

$\boldsymbol{A}=t \boldsymbol{C}^{p}$

$\mathbf{D}=\frac{t^{3}}{12} \boldsymbol{C}^{b}$

where $t$ corresponds to the thickness of the laminate. The elastic constants of Eqs. (8) and (10), as well as the yield curves for the resultants, are determined by subjecting the representative volume element (RVE) in Fig. 6 , to the corresponding stress states. In-plane properties are obtained using periodic boundary conditions (PBC). PBCs are necessary for periodicity to be maintained and to not overpredict stiffness when characterizing a single RVE, see e.g. Hammarberg et al. [26], Suquet [32], Xia et al. [33], Omairey et al. [34]. A short description of PBC is given in Sect. 2.5.

\subsection{Periodic boundary conditions}

The local strain, $\epsilon_{i k}$, is rewritten as

$\epsilon_{i k}=\bar{\epsilon}_{i k}+\epsilon_{i k}\left(u_{i}^{*}\right)$

where $\bar{\epsilon}_{i k}$ and $\epsilon_{i k}\left(u^{*}\right)$ are the average and fluctuating parts of the strain, and $u^{*}$ is a periodic displacement field. The 
Fig. 6 Representative volume element, with a top view in a and isometric view in $\mathbf{b}$

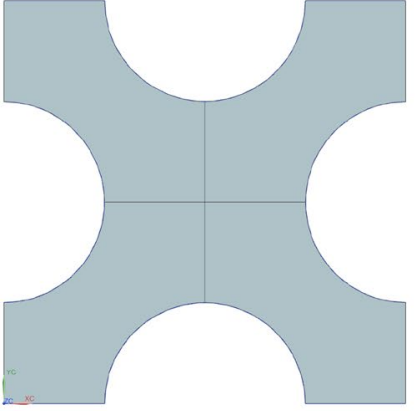

(a)

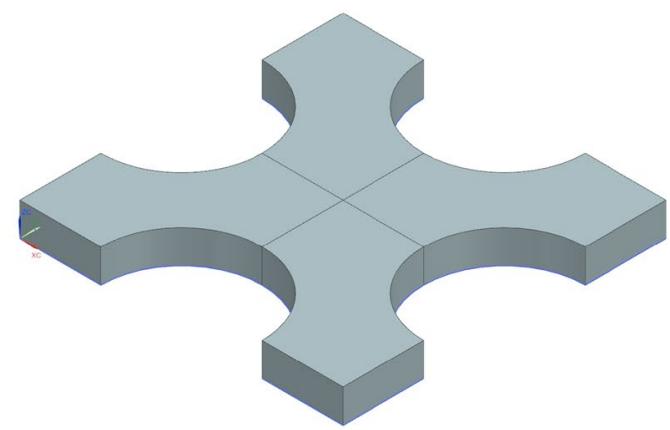

(b) periodicity condition for displacement on the boundary is obtained as

$u_{i}=\bar{\epsilon}_{i k} x_{k}+u_{i}^{*}$

where $x_{i}$ is the spatial coordinate and $i, k=(1,2,3)$. For the RVE in Fig. 6, the periodicity implies a coupling between nodes on opposite sides. Thus, from Eq. (16) the following equations can be formulated for nodes on the positive and negative faces of the RVE

$u_{i}^{+}=\bar{\epsilon}_{i k} x_{k}^{+}+u_{i}^{*}$

$u_{i}^{-}=\bar{\epsilon}_{i k} x_{k}^{-}+u_{i}^{*}$.

Equations (17) and (18) are rewritten as

$u_{i}^{+}-u_{i}^{-}=\bar{\epsilon}_{i k} x_{k}^{+}+u_{i}^{*}-\bar{\epsilon}_{i k} x_{k}^{-}+u_{i}^{*}=\bar{\epsilon}_{i k}\left(x_{k}^{+}-x_{k}^{-}\right)=\bar{\epsilon}_{i k} \Delta x_{k}$

which is rewritten by Xia et al. [33] as

$u_{i}^{j+}-u_{i}^{j-}=c_{i}^{j}$

where $i$ and $j$ relate to the degree of freedom (DOF) and the face connected to the node, and $i, j=(1,2,3)$ for $a$ three dimensional RVE.

In the present work, LS-DYNA is used to apply PBC on the RVE. The constant, $c_{i}^{j}$, in Eq. (20) corresponds to the displacement of dummy nodes, generated by the software, from which displacements and forces can be obtained. From the dummy nodes, the homogenized quantities for stress and strain are obtained. Initially, the deformation gradient, $F_{i j}$, is determined from the displacements of the dummy nodes as

$F_{i j}=\frac{\partial u_{i}}{\partial x_{j}}+\delta_{i j}=\frac{c_{i}^{j}}{\Delta x_{j}}+\delta_{i j}$ (no summation over indices). $\delta_{i j}$ and $\Delta x_{i}$ are the Kronecker delta and the dimension of the RVE respectively. Forces, $f_{i j}$, are extracted from the dummy nodes from which the macroscopic first Piola-Kirchhoff stress tensor, $P_{i j}$, is determined. The Green-Lagrange strain tensor, $E$, is obtained from the deformation gradient according to

$E_{i j}=\frac{1}{2}\left(F_{k i} F_{k j}-\delta_{i j}\right)$

The Cauchy stress tensor is obtained as

$\sigma_{i j}=J^{-1} P_{i k} F_{j k}$

where $J$ is the determinant of the deformation gradient, i.e. the Jacobian. From Eqs. (22) and (23), the homogenized constitutive relationship for various loading conditions can be determined.

\section{Results and discussion}

Several finite element simulations were utilized to investigate the energy absorption of the ultra high strength sandwich concept. Initially, a quasi-static check and a mesh convergence study were conducted. In the subsequent simulations, energy absorption of the sandwich and its constituents were studied for several sandwich layouts (see Table 1).

\subsection{Quasi-static check and mesh convergence}

To ensure quasi-static conditions were met, sandwich \#1 of Table 1, was subjected to the three velocity curves of Fig. 7a. Comparing the quotient between kinetic and internal energy, see Fig. 7b, and the force-displacement curves of Fig. 7c, where the accumulated internal energy is presented in the legend, indicated that velocity curve \#01 ensured quasi-static conditions. The difference between velocity curve \#01 and \#02, in terms of accumulated internal energy, was $\approx 1.8 \%$ and since the force-displacement 
Fig. 7 The response obtained for the three tool velocity curves in a are investigated with respect to the kinetic energy in $\mathbf{b}$ and the force response in c to ensure negliable dynamic effects. The results are presented for Sandwich 1 in Table 1

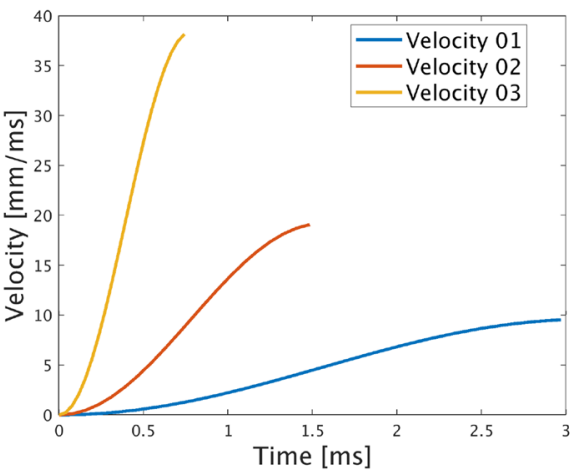

(a)

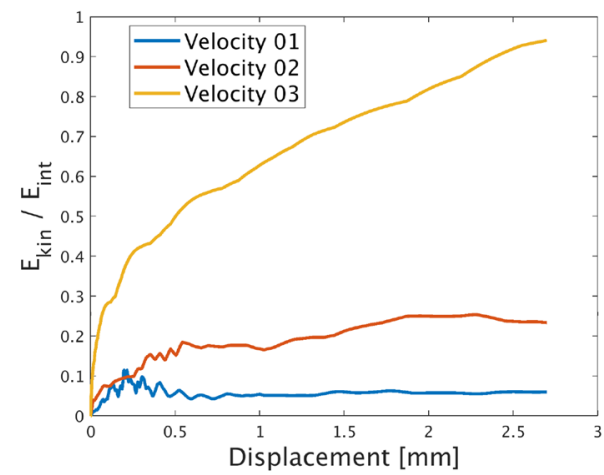

(b)

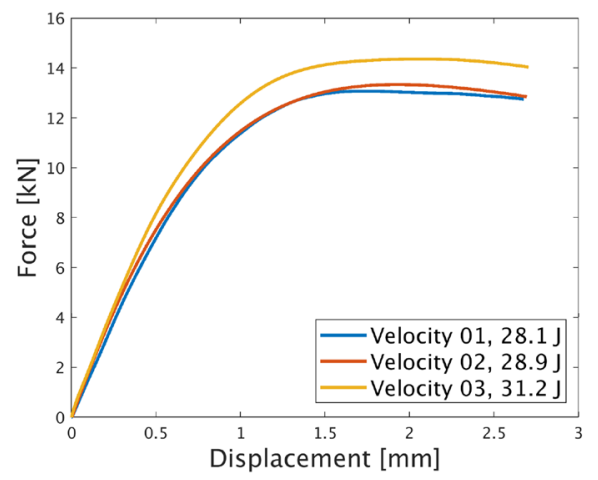

(c)

responses were similar, velocity curve \#01 was chosen for the remaining simulations.

The results obtained from the mesh convergence study are presented in Fig. 8a, where internal energy together with CPU time is presented for each level of mesh refinement. The corresponding force-displacement response is presented in Fig. $8 \mathrm{~b}$. It is noted that the model with two solid elements through the thickness produces adequate results with respect to the internal energy as only small differences are observed for the subsequent mesh refinements. When comparing the force-displacement responses it is clear that four elements through the thickness is necessary to get a converged response over the entire range of displacement. Thus four solid elements through the thickness was chosen, providing a good trade off between accuracy and CPU time.

\subsection{Energy absorption of sandwiches}

Eleven sandwiches (Table 1) were evaluated numerically for energy absorption in order answer the question if the suggested UHSS sandwich concept is a contender for increasing specific energy absorption, as compared to solid hat profiles of equivalent weight. In the models,
Fig. 8 For the mesh convergence study four levels of mesh refinements are used: 1 , 2, 4 and 8 fully integrated cubic solid elements through the thickness. In a internal energy and computational time are are presented versus number of elements. For each mesh size the force-displacement response is presented in $\mathbf{b}$

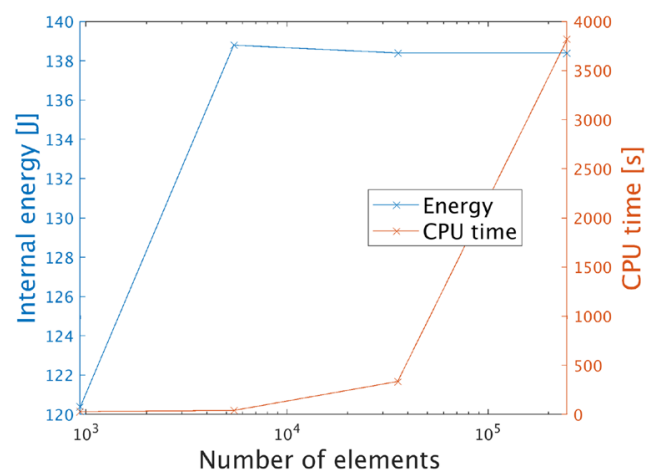

(a)

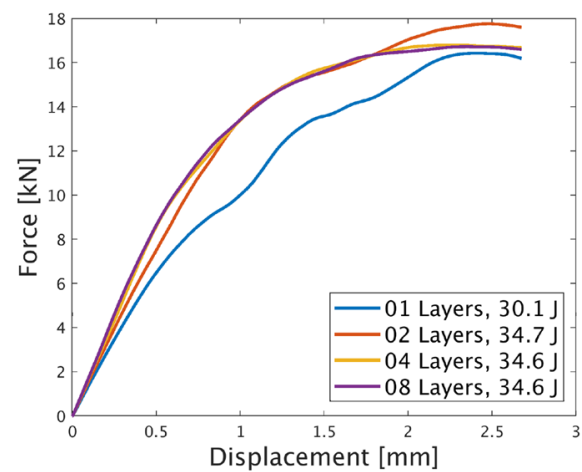

(b) 
Table 2 For the sandwich hat profiles mass and specific energy absorption (SEA)

summarized in the table

\begin{tabular}{lllllllllll}
\hline Sandwich & 1 & 2 & 3 & 4 & 5 & 6 & 7 & 8 & 9 & 10 \\
\hline Mass (g) & 17.9 & 13.4 & 8.95 & 17.6 & 18.9 & 18.6 & 17.2 & 17.9 & 13.4 & 8.95 \\
SEA (J/g) & 6.28 & 5.84 & 4.36 & 6.12 & 6.48 & 6.68 & 5.16 & 9.04 & 6.72 & 4.68 \\
\hline
\end{tabular}

skin fracture was included by a damage model calibrated for shell elements under plane stress conditions. Results are presented until the point of sandwich skin fracture, comparing both sandwiches and equivalent models for a given intrusion. To illustrate the deformation mode, the initial and final state are presented for sandwich \#1 and \#3 in Fig. 9.

In Fig. 10a, sandwiches \#1-3, with hole diameters of $3 \mathrm{~mm}$, are represented by the solid lines. Each sandwich was compared to a solid hat profile of equivalent weight, represented by the dashed lines in the figure. For each sandwich, the results are presented up until the point of skin fracture, at which point the curves are cut off. For sandwich \#1, the accumulated damage just before fracture is presented in Fig. 11a and after fracture in Fig. 11b. In the figure, the concentration of damage occurs near the top rows of holes, corresponding to the concentration of effective plastic strain, see Fig. 12a.

To evaluate the impact of the hole diameter on the sandwich response, a diameter of $1.5 \mathrm{~mm}$ was also evaluated, corresponding to sandwich \#8-10. The force-displacement response is presented in Fig. 10b, cut off at the point of skin fracture. The accumulated damage is presented before and after skin fracture in Fig. 11c, d for sandwich \#8. As for a hole diameter of $3 \mathrm{~mm}$, the concentration of damage is located near the top row of the holes with some additional concentrations at the top radius. However, the main part of the fracture for sandwich \#8 still occurs in a similar location as for sandwich \#1.

From the results presented in Fig. 10, it was noted that by utilizing the sandwich concept, the specific energy absorption was increased by approximately $8-17 \%$, as compared to the solid hat profiles. A main difference observed was the impact of the hole diameter on the sandwich ductility. For all the sandwiches, the smaller hole diameter allowed for a greater displacement before fracture, but the effect is particularly clear for sandwich \#1
Fig. 9 The initial and final states are presented for sandwich \#1 and \#3 to illustrate the loading case and deformation mode used for evaluating the energy absorption of the sandwich concept

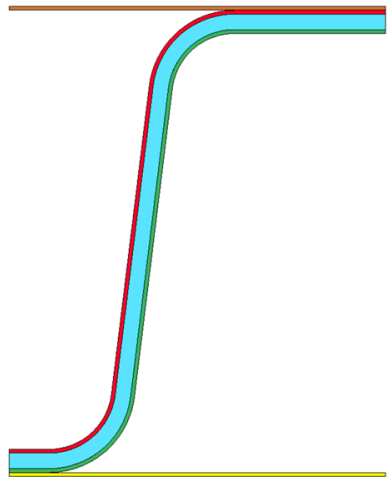

(a)

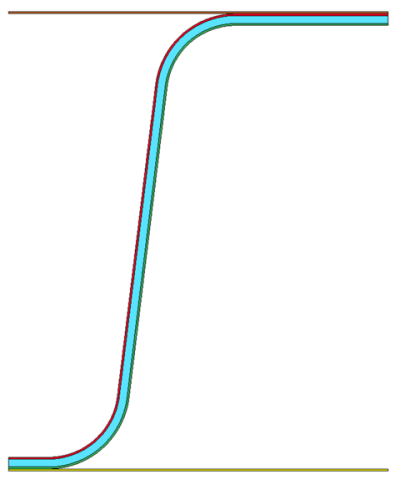

(c)

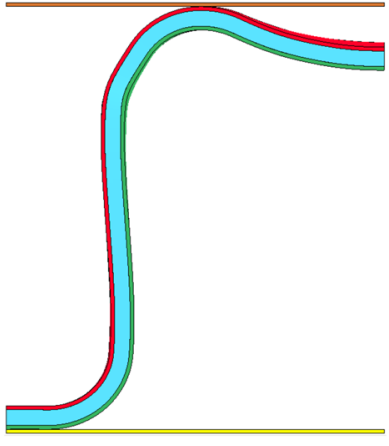

(b)

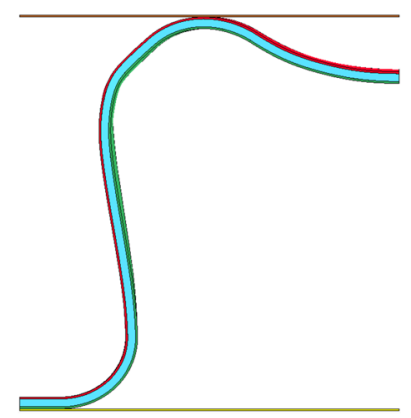

(d)

SN Applied Sciences 

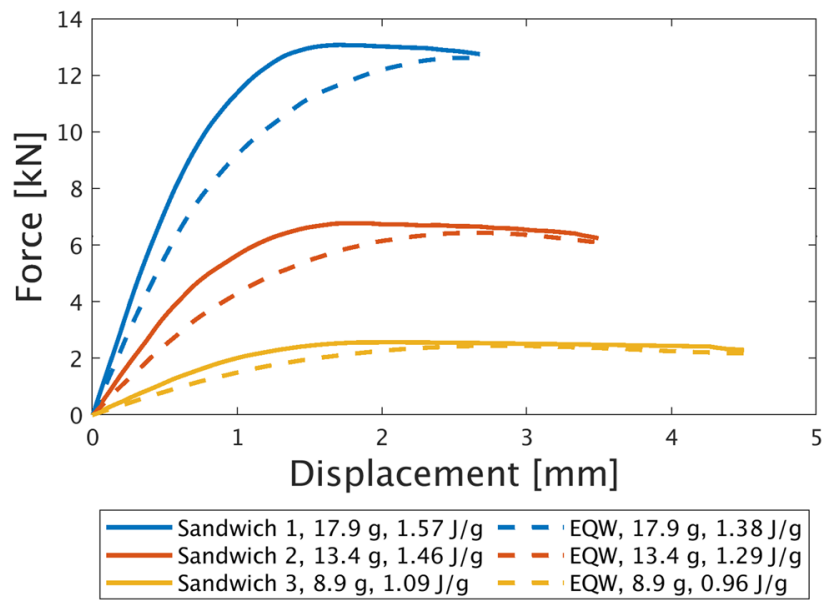

(a)
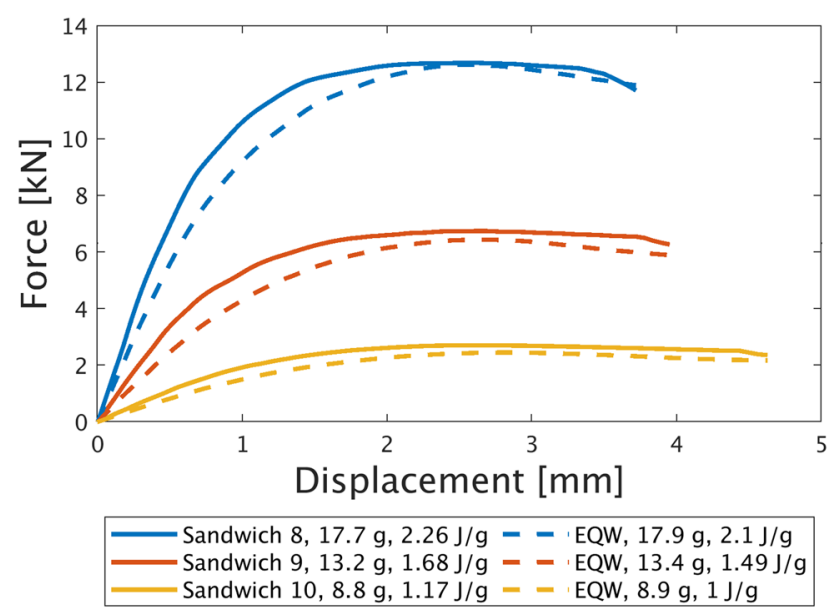

(b)

Fig. 10 Sandwiches with varying thickness and hole diameter are compared with respect to energy absorption. In a a hole diameter of $3 \mathrm{~mm}$ is used and a hole diameter of $1.5 \mathrm{~mm}$ is used in $\mathbf{b}$. The blue, red and yellow lines correspond to sandwich thicknesses of $1.848,1.386$ and $0.924 \mathrm{~mm}$ respectively. Each sandwich is compared to a solid hat-profile of equivalent weight (EQW) in the figure, represented by the dashed lines

and \#8 where the difference in allowable displacement is approximately $50 \%$ in favor of the latter. This also emphasises the importance of including fracture models for evaluations of sandwich concepts, as the point of fracture is greatly affected by the layout of the sandwich. Thus, it would be beneficial to also include a fracture model calibrated for solid elements, making it possible to predict core fracture as well. In this work, the fracture model had been calibrated for plane stress and no data was available for solid elements which is why only skin fracture was studied.

To evaluate the contribution by the sandwich constituents, core and skins, the hole distribution was varied while the thickness of the layers were held constant. For sandwich \#4 and \#5 the hole spacing was increased and decreased by $25 \%$ respectively. The force-displacement response is presented in Fig. 13a, with sandwich \#1 as a reference. Additionally, for sandwich \#6 and \#7, the hole distributions and total thicknesses were held constant while the layer thicknesses were varied. The force-displacement response is presented in Fig. 13b. The intention with comparing sandwiches \#1 and \#4-7 was to evaluate how the layout of the sandwich affected the energy absorption. From the results it was observed that adding mass to the sandwich increased its energy absorption, but more importantly, it was noted that the placement of the mass mattered. The further away from the neutral layer that mass was added the greater was the effect on specific energy absorption. When sandwich \#4 and \#5 were compared, the difference in mass was found to be $7.4 \%$ whereas the difference in SEA was only $5.9 \%$. A similar comparison for sandwich \#6 and \#7 indicated an increase of SEA of $30 \%$ whereas the weight had only been increased by $8 \%$. A comparison between sandwich \#5 and \#6 was also done. Sandwich \#5 with a mass of $18.9 \mathrm{~g}$ exhibited a lower SEA compared to sandwich \#6 with a mass of $18.6 \mathrm{~g}$. The greater SEA was attributed to the fact that sandwich \#6 had a larger portion of its mass further away from the neutral layer, where the bending stress is zero, due to its core thickness. The distribution of the internal energy of the sandwich constituents is presented in Fig. 14. It was noted that the major difference between the two sandwiches was the contribution by the lower skin of sandwich \#6, which had a significantly higher energy absorption compared to the other layers. A summary of the performance of the sandwiches in terms of SEA is presented in Table 2.

The weight saving potential of the sandwich was also evaluated. This was done by comparing the weights of a solid and a sandwich hat-profile with similar energy absorption. The obtained results are presented in Fig. 15, from which it was found that the weight could be lowered by approximately $7 \%$.

An effort was made to reduce computational time by replacing the perforated sections of the core with an equivalent material. The equivalent material was modeled using a constitutive routine based on a stress-resultant formulation. Two sets of elastic constants were required, corresponding to in-plane loading and bending respectively, presented in Table 3. Plasticity was modeled by specifying uncoupled yield curves for the resultants, see Fig. 16a, b. For the elastic constants differences were observed for both Young's modulus and Poisson's ratio. This indicated the necessity for the constitutive routine to make a distinction between in-plane loading and bending, motivating the chosen material model. From the results presented in 
Fig. 11 The accumulated damage parameter before and after fracture is presented for sandwich 1 in $\mathbf{a}, \mathbf{b}$ and for sandwich 8 in $\mathbf{c}, \mathbf{d}$

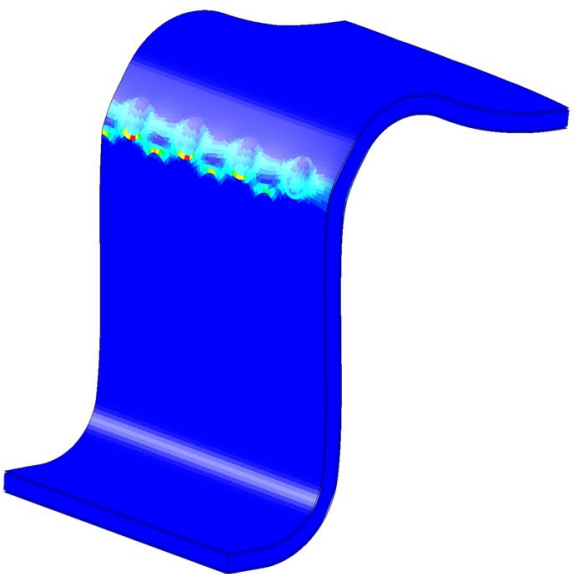

(a)

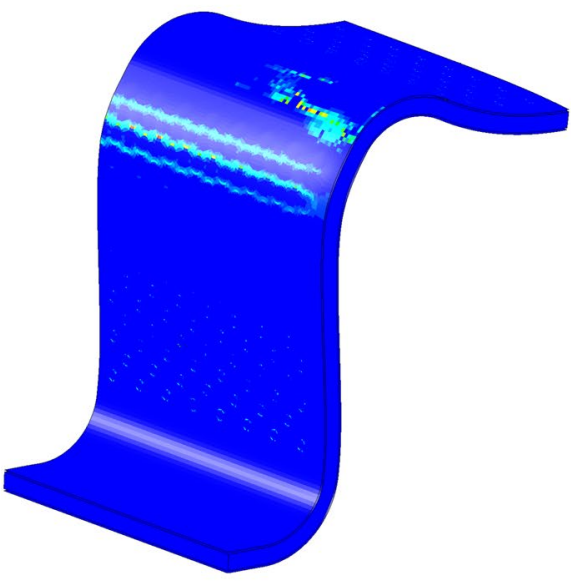

(c)

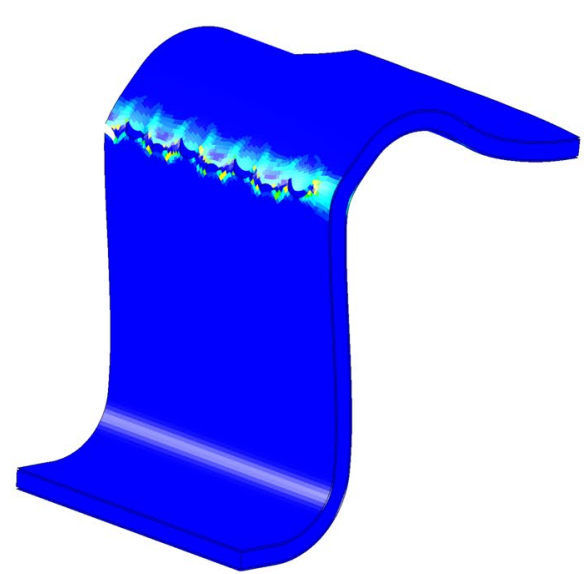

(b)

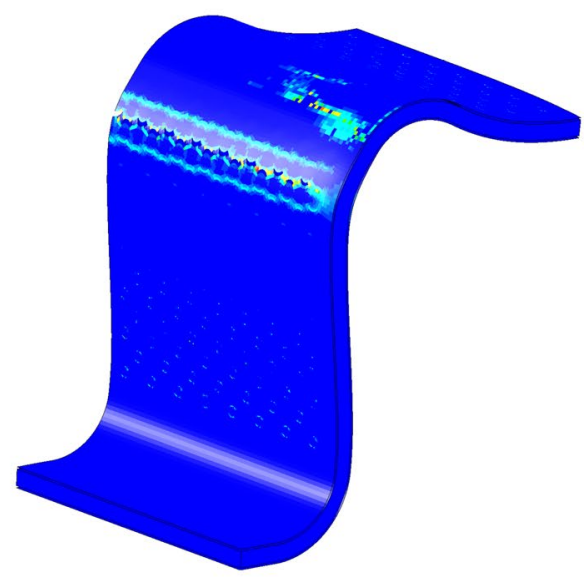

(d)

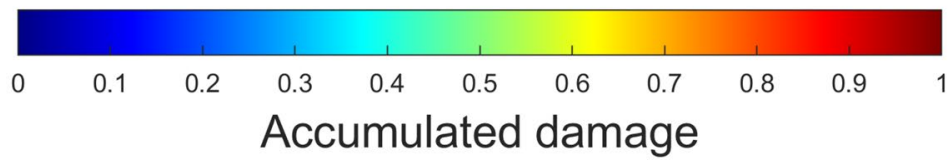

Fig. 16c, it was found that the homogenized model captured the overall force-displacement response quite well while reducing computational time with approximately $95 \%$. The energy absorption of the homogenized model corresponds well to the detailed model, both absorbing $112.4 \mathrm{~J}$. However, the homogenized model was not able to predict fracture corresponding to what was observed in the detailed models. In the detailed models fracture consistently occurred due to the holes of the core, whereas the homogenized predicts failure at a much later stage occurring over the top radius in the skin.

The results of the present study should be compared to the results obtained by Mohr and Wierzbicki [27], where a similar sandwich concept was utilized for crash boxes.
According to Mohr and Wierzbicki [27] the specific energy absorption remained constant regardless of the distribution of core and skins, and redistribution of mass away from the neutral layer did contribute to increasing the SEA. A major difference between [27] and the present study is the usage of detailed FE models. In the work done by Mohr and Wierzbicki [27] homogenized models, based on a honeycomb model available within LS-DYNA [28], was utilized for representing the core, where as the present work used detailed FE models for analyzing the sandwich concept.

Debonding is an important failure mode for laminates and skins, which was not studied in the present work but would be necessary for better predictions of the sandwich performance.

\section{SN Applied Sciences}


Fig. 12 Effective plastic strain before fracture for sandwich 1 in $\mathbf{a}$ and sandwich 8 in $\mathbf{b}$

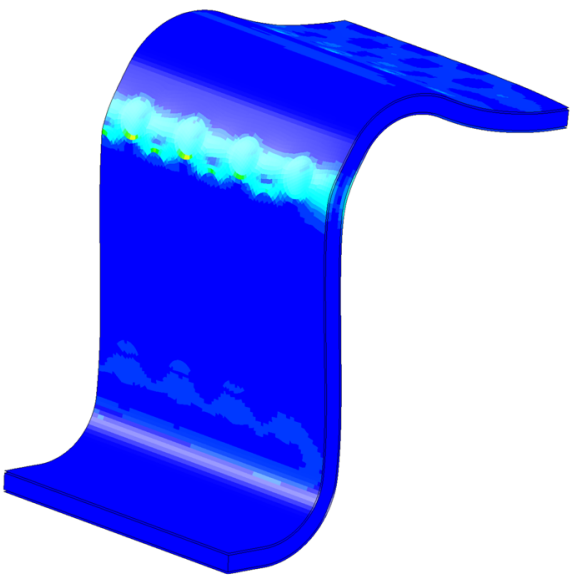

(a)

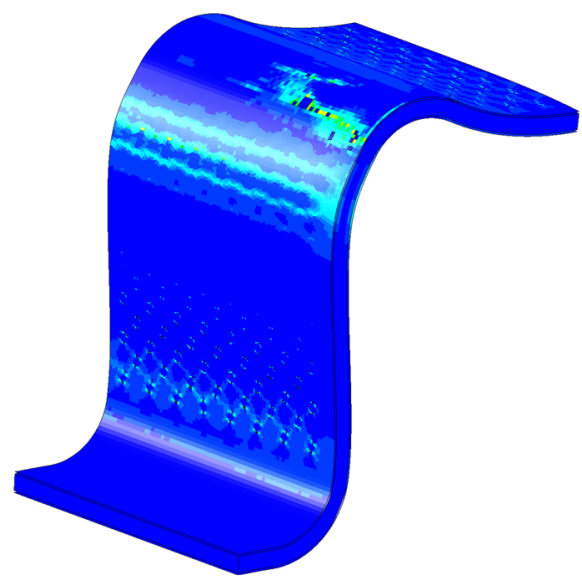

(b)

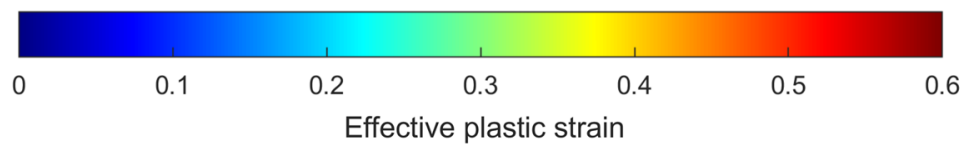

Fig. 13 Comparing forcedisplacement response and energy absorption when varying hole distribution and core and skin thickness. The total thickness and hole diameter are kept constant at $1.848 \mathrm{~mm}$ and $3 \mathrm{~mm}$ respectively
Fig. 14 Comparing energy absorption for sandwich constituents when varying hole distribution and core and skin thickness. The total thickness and hole diameter are kept constant at $1.848 \mathrm{~mm}$ and $3 \mathrm{~mm}$ respectively

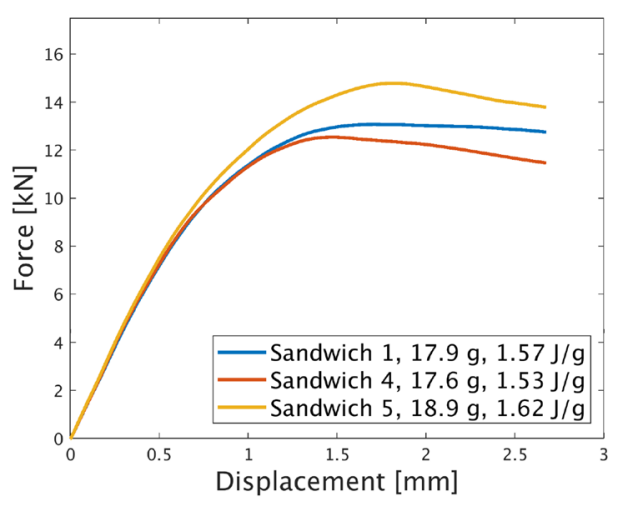

(a) Force-displacement response when varying hole distribution.

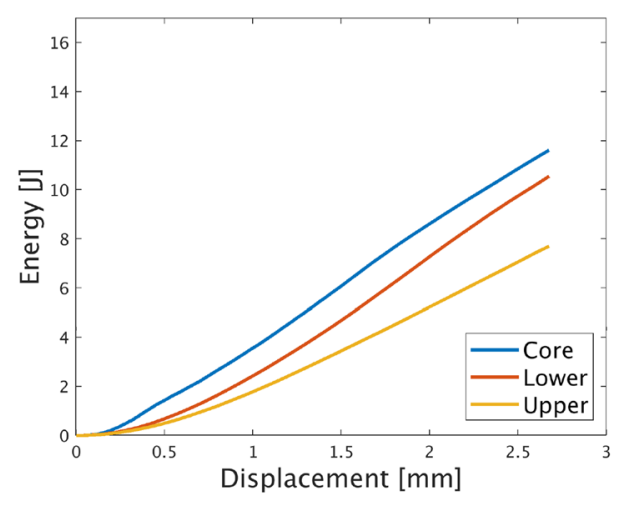

(a) Internal energies for skins and core of sandwich 5 .

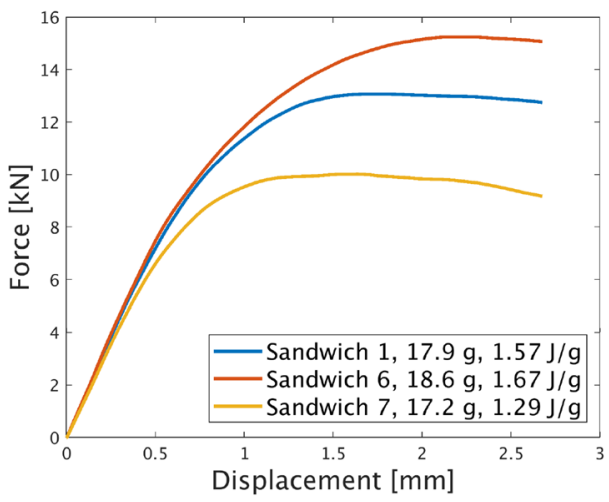

(b) Force-displacement response when varying core and skin thickness

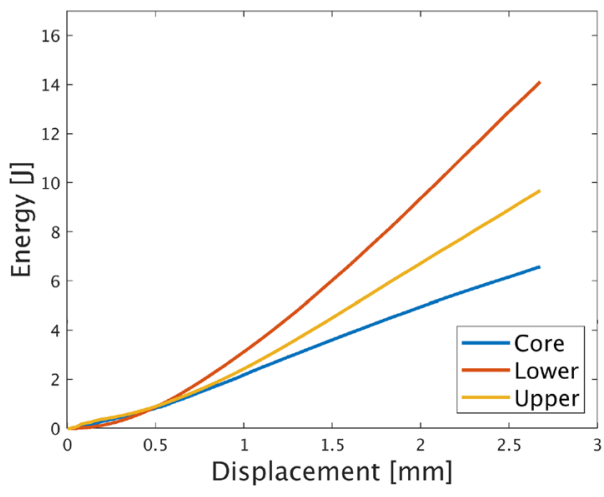

(b) Internal energies for skins and core of sandwich 6 


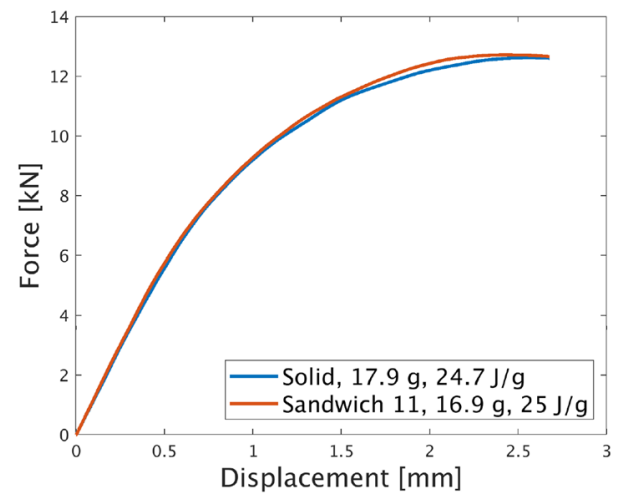

Fig. 15 To illustrate the weight saving potential of the sandwich concept, a solid hat is compared to a sandwich with equivalent energy absorption

The present work highlights the importance of accurate representation of the perforated core, with respect to the distribution of mass around the neutral layers. Alternatively, a constitutive model accounting for the phenomena observed in the present study should be utilized. A constitutive model, developed for perforated sheets, should also be considered as it could drastically reduce computational time.

\section{Conclusions}

The present study investigated the possibility of utilizing ultra-high strength steel in sandwich structures for energy absorption applications. It was found that the suggested sandwich concept provides a means for increasing specific energy absorption of components, and a weight saving potential for equal performance. The models used can be a tool for lightweight component development for energy absorption applications. Distribution of mass was shown to be of importance, since displacing the mass away from the neutral layers increased specific energy absorption. Inclusion of fracture models are required for correctly predicting sandwich performance, since skin fracture occurred earlier in the sandwich hat-profiles as compared
Table 3 Elastic constants used for the equivalent material using the stress-resultant based constitutive model

Fig. 16 Input data used for the equivalent material model, see Eq. (12), is presented in $\mathbf{a}$, b and the force-displacement and energy absorption of the detailed and homogenized model of sandwich 1 are presented in c

\begin{tabular}{llllllll}
\hline & $E_{11}(\mathrm{GPa})$ & $E_{22}(\mathrm{GPa})$ & $\nu_{12}(-)$ & $\nu_{21}(-)$ & $G_{12}(\mathrm{GPa})$ & $G_{23}(\mathrm{GPa})$ & $G_{31}(\mathrm{GPa})$ \\
\hline In-plane & 46.3 & 46.3 & 0.5 & 0.5 & 35.3 & 33.3 & 33.3 \\
Bending & 78.4 & 78.4 & 0.2 & 0.2 & 35.2 & - & -
\end{tabular}

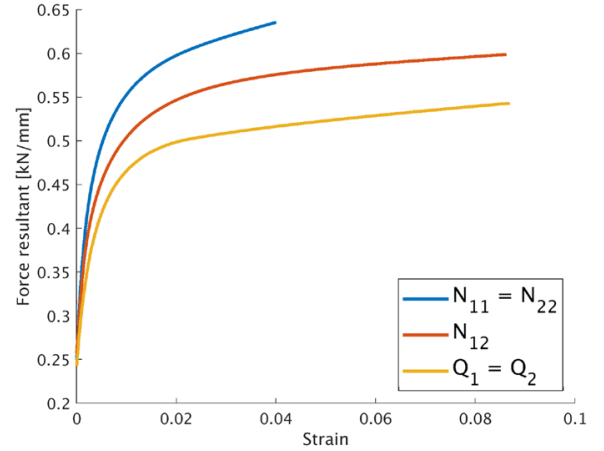

(a)

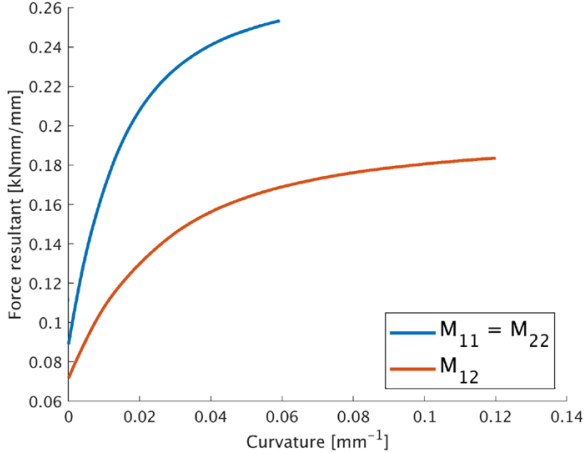

(b)

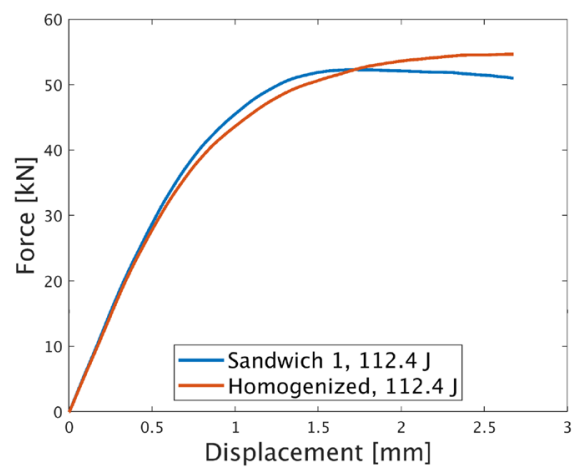

(c) 
to the solid hat-profiles. Furthermore, constitutive models must distinguish between in-plane loading and bending due to the differences in elastic constants for each loading cases. Homogenization of the perforated core can be utilized for reduction of computational time with maintained accuracy. A limit of the present study, is that a perfect bond was assumed between the layers of the sandwiches and delamination was not studied.

In summary, methods for reducing weight, by introducing light and strong materials and structures, are of importance for meeting demands regarding reduction of emissions from the automotive industry. The numerical models of the suggested UHSS sandwich concept provides a way of increasing specific energy absorption. This indicates that a weight saving potential exists by utilizing sandwich structures for energy absorption applications.

In summary, methods for reducing weight, by introducing light and strong materials and structures, are of importance for meeting demands regarding reduction of emissions from the automotive industry. The numerical models of the suggested UHSS sandwich concept provides a way of increasing specific energy absorption. This indicates that a weight saving potential exists by utilizing sandwich structures for energy absorption applications.

Acknowledgements The authors would like to thank Mikael Schill at DYNAmore Nordic for the calibrated GISSMO data used in the present study. Economic support is supplied through the Swedish lightweight innovation programme-LIGHTer, which is gratefully acknowledged.

Funding Open access funding provided by Lulea University of Technology. This study was funded by Swedish lightweight innovation programme-LIGHTer (Ref. No. 2016-04343).

\section{Compliance with ethical standards}

Conflict of interest On behalf of all authors, the corresponding author states that there is no conflict of interest.

Open Access This article is licensed under a Creative Commons Attribution 4.0 International License, which permits use, sharing, adaptation, distribution and reproduction in any medium or format, as long as you give appropriate credit to the original author(s) and the source, provide a link to the Creative Commons licence, and indicate if changes were made. The images or other third party material in this article are included in the article's Creative Commons licence, unless indicated otherwise in a credit line to the material. If material is not included in the article's Creative Commons licence and your intended use is not permitted by statutory regulation or exceeds the permitted use, you will need to obtain permission directly from the copyright holder. To view a copy of this licence, visit http://creativecommons .org/licenses/by/4.0/.

\section{References}

1. Kawajiri K, Kobayashi M, Sakamoto K (2020) Lightweight materials equal lightweight greenhouse gas emissions?: A historical analysis of greenhouse gases of vehicle material substitution. J Clean Prod 253:119805

2. Karbasian H, Tekkaya AE (2010) A review on hot stamping. J Mater Process Technol 210(15):2103-2118. https://doi. org/10.1016/j.jmatprotec.2010.07.019

3. Oldenburg M, Lindkvist G (2011) Tool thermal conditions for tailored material properties. HTM J Heat Treat Mater 66(6):329-334. https://doi.org/10.3139/105.110121

4. Oldenburg M (2014) Warm forming of steels for tailored microstructure. In: Hetnarski RB (ed) Encyclopedia of thermal stresses. Springer, Dordrecht. https://doi. org/10.1007/978-94-007-2739-7_466

5. Merklein Marion, Wieland Michael, Lechner Michael, Bruschi Stefania, Ghiotti Andrea (2016) Hot stamping of boron steel sheets with tailored properties: a review. J Mater Process Technol 228:11-24. https://doi.org/10.1016/j.jmatprotec.2015.09.023

6. Östlund R, Oldenburg M, Häggblad HÅ, Berglund D (2013) Evaluation of localization and failure of boron alloyed steels with different microstructure compositions. J Mater Process Technol. https://doi.org/10.1016/j.jmatprotec.2013.09.022

7. Golling S, Frómeta D, Casellas D, Jonsén P (2018a) Influence of microstructure on the fracture toughness of hot stamped boron steel. Mater Sci Eng 743:529-539. https://doi.org/10.1016/j. msea.2018.11.080

8. Golling S, Frómeta D, Casellas D, Jonsén P (2018b) Investigation on the influence of loading-rate on fracture toughness of AHSS grades. Mater Sci Eng A 726:332-341. https://doi.org/10.1016/j. msea.2018.04.061

9. Hara D, Özgen GO (2016) Investigation of weight reduction of automotive body structures with the use of sandwich materials. In: Rafalski L, Zofka A (eds) Transportation research procedia, vol 14. Elsevier B.V., pp 1013-1020. https://doi.org/10.1016/j.trpro .2016.05.081

10. Balakrishnan BS, Hart-Rawung T, Buhl J, Seidlitz H, Bambach M (2020) Impact and damage behaviour of FRP-metal hybrid laminates made by the reinforcement of glass fibers on $22 \mathrm{MnB5}$ metal surface. Compos Sci Technol. https://doi.org/10.1016/j. compscitech.2019.107949

11. Gibson LJ (2000) Mechanical behavior of metallic foams. Ann Rev Mater Sci 30(1):191-227. https://doi.org/10.1146/annur ev.matsci.30.1.191

12. Smith BH, Szyniszewski S, Hajjar JF, Schafer BW, Arwade SR (2012a) Steel foam for structures: a review of applications, manufacturing and material properties

13. Park C, Nutt SR (2000) PM synthesis and properties of steel foams. Mater Sci Eng A 288(1):111-118. https://doi.org/10.1016/ S0921-5093(00)00761-9

14. Smith B, Szyniszewski S, Hajjar J, Schafer B, Arwade S (2012b) characterization of steel foams for structural components. Metals 2(4):399-410. https://doi.org/10.3390/met2040399

15. Szyniszewski S, Smith B, Arwade S, Hajjar J, Benjamin S (2012) Tensile and shear element erosion in metal foams. Technical report 1. http://www.steelfoam.org/ls-dyna_szyniszewski_03. pdf

16. Szyniszewski ST, Smith BH, Hajjar JF, Schafer BW, Arwade SR (2014) The mechanical properties and modeling of a sintered hollow sphere steel foam. Mater Des 54:1083-1094. https://doi. org/10.1016/j.matdes.2013.08.045

17. Zhang Y, Sun G, Xu X, Li G, Huang X, Shen J, Li Qing (2013) Identification of material parameters for aluminum foam at high strain 
rate. Comput Mater Sci 74:65-74. https://doi.org/10.1016/j. commatsci.2013.02.024

18. Sulong MA, Vesenjak M, Belova IV, Murch GE, Fiedler T (2014) Compressive properties of advanced Pore Morphology (APM) foam elements. Mater Sci Eng A 607:498-504. https://doi. org/10.1016/j.msea.2014.04.037

19. Xiao Z, Fang J, Sun G, Li Q (2015) Crashworthiness design for functionally graded foam-filled bumper beam. Adv Eng Softw 85:81-95. https://doi.org/10.1016/j.advengsoft.2015.03.005

20. Marsavina Liviu, Kováčik Jaroslav, Linul Emanoil (2016) Experimental validation of micromechanical models for brittle aluminium alloy foam. Theor Appl Fract Mech 83:11-18. https:// doi.org/10.1016/j.tafmec.2015.12.020'

21. Özer H, Can Y, Yazici M (2017) Investigation of the crash boxes Light weighting with syntactic foams by the finite element analysis. Acta Physica Polon A 132:734-737. https://doi.org/10.12693 /APhysPolA.132.734

22. Aktay Levent, Johnson Alastair F, Kröplin Bernd H (2008) Numerical modelling of honeycomb core crush behaviour. Eng Fract Mech 75(9):2616-2630. https://doi.org/10.1016/j.engfracmec h.2007.03.008

23. Nayak SK, Singh AK, Belegundu AD, Yen CF (2013) Process for design optimization of honeycomb core sandwich panels for blast load mitigation. Struct Multidiscip Optim 47(5):749-763. https://doi.org/10.1007/s00158-012-0845-x

24. Sun Guangyong, Huo Xintao, Chen Dongdong, Li Qing (2017) Experimental and numerical study on honeycomb sandwich panels under bending and in-panel compression. Mater Des 133:154-168. https://doi.org/10.1016/j.matdes.2017.07.057

25. Yinghan Wu, Liu Qiang, Jie Fu, Li Qing, Hui David (2017) Dynamic crash responses of bio-inspired aluminum honeycomb sandwich structures with CFRP panels. Composit Part B Eng 121:122133. https://doi.org/10.1016/j.compositesb.2017.03.030

26. Samuel Hammarberg, Jörgen Kajberg, Simon Larsson, Pär Jonsén (2020) Ultra high strength steel sandwich for lightweight applications. SN Appl Sci 2(6):2523-3963. https:// doi.org/10.1007/s42452-020-2773-5

27. Dirk M, Tomasz W (2006) On the crashworthiness of shearrigid sandwich structures. J Appl Mech 73(4):633. https://doi. org/10.1115/1.2165232

28. LS-DYNA Keyword User's Manual (2018)

29. Golling S, Östlund R, Oldenburg M (2016) Characterization of ductile fracture properties of quench-hardenable boron steel: influence of microstructure and processing conditions. Mater Sci Eng A 658:472-483. https://doi.org/10.1016/j.msea.2016.01.091

30. Nielen S, Anirban B, Willem R, Katharina W, Dipl-Math Trent E, Tushar G, Ken C (2019) LS-OPT ${ }^{\oplus}$ user's manual a design optimization and probabilistic analysis tool for the engineering analyst. Technical report, www.Istc.com

31. Jones RM (1999) Mechanics of composite materials, 2nd edn. Taylor \& Francis Group. ISBN: 9781560327127

32. Pierre $S$ (1987) Elements of homogenization theory for inelastic solid mechanics. In: Sanchez-Palencia E, Zaoui A (eds) Homogenization techniques for composite media. Springer, Berlin, pp 194-275

33. Zihui X, Yunfa Z, Fernand E (2003) A unified periodical boundary conditions for representative volume elements of composites and applications. Int J Solids Struct 40(8):1907-1921. https://doi. org/10.1016/S0020-7683(03)00024-6

34. Omairey Sadik L, Dunning Peter D, Sriramula Srinivas (2019) Development of an ABAQUS plugin tool for periodic RVE homogenisation. Eng Comput 35(2):567-577. https://doi. org/10.1007/s00366-018-0616-4

Publisher's Note Springer Nature remains neutral with regard to jurisdictional claims in published maps and institutional affiliations. 